\title{
INSTITUCIONES LOCALES \\ Y EL IMPUESTO PREDIAL RURAL EN COLOMBIA, $1998-2010^{*}$
}

Recibido: 10 de junio de 2016 - Aprobado: 08 de diciembre de 2016

DOI: $10.22395 /$ seec.v20n42a7

Marta Juanita Villaveces Niño**

\section{RESUMEN}

El objetivo de este trabajo es analizar el comportamiento del impuesto a la propiedad rural en Colombia durante el período 1998 y 2010 . La estrategia metodológica incluye el cálculo de seis variables relacionadas con el recaudo del impuesto a la propiedad y cuatro variables institucionales locales, organizadas por grupos de municipios; con estos indicadores se realiza un análisis descriptivo para identificar el desempeño del predial por grupos de municipios. Los resultados sugieren la existencia de un comportamiento heterogéneo entre los diferentes municipios, explicado, en gran parte, por variables institucionales como la concentración de la tierra, la concentración política y la presencia de actores al margen de la ley capaces de capturar el poder local.

\section{PALABRAS CLAVE}

Impuesto predial rural; instituciones locales; análisis regionales; Colombia

\section{CLASIFICACIÓN JEL}

\author{
$\mathrm{H} 71$; R51
}

\section{CONTENIDO}

Introducción; 1. Instituciones locales y tributación; 2. Legislación del impuesto a la propiedad; 3. Comportamiento del impuesto a la propiedad rural 4; Conclusiones y recomendaciones; Bibliografía.

Este artículo de investigación hace parte de la investigación titulada "Interrelación entre la concentración política y su efecto sobre la tributación rural en Colombia", financiado por el Fondo para la Investigación de la Universidad del Rosario. El periodo de ejecución de la investigación es octubre 2015 a octubre 2016 y fue desarrollado en el Grupo de Investigación de la Facultad de Economía de la Universidad del Rosario, clasificado A por Colciencias. Agradezco a Juan Fernando Vargas los valiosos comentarios y los datos suministrados y a los tres evaluadores anónimos, sus útiles comentarios, sugerencias y las últimas correcciones al manuscrito.

** Economista, Universidad Nacional, Bogotá, Colombia. MSc en Política Comparada, London School of Economics, Londres, Inglaterra. PhD en Estudios Políticos, Universidad Externado de Colombia, Bogotá, Colombia. Profesora, Escuela de Economía, Universidad Nacional de Colombia, Bogotá, Colombia. Tel: 3165000 ext.12381. Correo electrónico: mjvillavecesn@unal.edu.co. 


\section{LOCAL INSTITUTIONS AND RURAL PROPERTY TAX IN COLOMBIA, 1998-2010 ABSTRACT}

The main goal this paper has is to analyze the behavior or rural property tax in Colombia between 1998 and 2010. The methodological structure includes calculating six variables related with property tax collection and four local institutional variables, which are organized by municipality; using these indicators, a descriptive analysis is done in order to identify property performance per municipality group. Results suggest the existence of a heterogeneous behavior between different municipalities, largely explained by institutional variables such as land concentration, political concentration and the presence of illegal groups that have the possibility of replacing local power

\section{KEY WORDS}

Rural property tax; local institutions; regional analysis; Colombia.

\section{JEL CLASSIFICATION}

H71; R51

\section{CONTENT}

Introduction; 1. Taxation and local institutions; 2. Property tax legislation; 3. Rural property tax behavior; 4 . Conclusions and recommendations; Bibliography.

\section{INSTITUIÇÕES LOCAIS E O IMPOSTO TERRITORIAL RURAL NA COLÔMBIA, $1998-2010$ \\ RESUMO}

O objetivo deste trabalho é analisar o comportamento do imposto à propriedade rural na Colômbia durante o período 1998 e 2010. A estratégia metodológica inclui o cálculo de seis variáveis relacionadas com a arrecadação do imposto à propriedade e quatro variáveis institucionais locais, organizadas por grupos de municípios; com estes indicadores se realiza uma análise descritiva para identificar o desempenho do ITR por grupos de municípios. Os resultados sugerem a existência de um comportamento heterogêneo entre os diferentes municípios, explicado em grande parte por variáveis institucionais como a concentração da terra, a concentração política e a presença de atores à margem da lei capazes de capturar o poder local.

\section{PALAVRAS CHAVE}

Imposto Territorial Rural; instituições locais; análise regionais; Colômbia.

\section{CLASSIFICAÇÃO JEL}

$\mathrm{H} 71$; R51

\section{CONTEÚDO}

Introdução; 1. Instituições locais e tributação; 2. Legislação do imposto à propriedade

3. Comportamento do imposto à propriedade rural 4; Conclusões e recomendações: Bibliografia. 


\section{INTRODUCCIÓN}

En su novela, El ruido de las cosas al caer, Vásquez (2011, p. 34) se refiere a los dueños de la tierra así: "[... los terratenientes de Bogotá y Medellín, una especie de poderes ausentes que tenían la tierra, pero nunca estaban en ella, y vivían de ella, pero nunca pagaban los impuestos que ella les causaba [...]". Esta visión, según la cual los grandes dueños de tierra tienen un enorme poder local, pero no pagan impuestos, no es exclusiva de la literatura. A su vez, en la revista Semana en el año $2003^{1}$ se afirma que los esfuerzos del impuesto a la propiedad se han concentrado en la ciudad y han dejado al campo en un rezago que favorece los intereses de los propietarios de grandes extensiones de tierra en Colombia. ¿Qué puede explicar estas afirmaciones del bajo nivel de pago del impuesto a la propiedad rural en Colombia y su vínculo con intereses locales o regionales?

La literatura académica que da explicaciones a la falta de pago de impuestos de los grandes propietarios rurales es amplia. En general, se subraya el bajo nivel de pago del predial rural. Varios autores han argumentado que el pago del impuesto a la propiedad rural es casi inexistente, por cuenta de tres situaciones: el sistema de administración del impuesto, la cultura de no pago de los contribuyentes, las instituciones regionales o locales y el conflicto armado. Entre estos autores se destacan Kalmanovitz (2010), Kalmanovitz y López (2007 y 2008), Machado (1990 y 1998), Reyes (2008 y 2009) y Echavarría (1987), entre otros. Según el enfoque administrativo, el bajo nivel de pago está asociado a la manera en que los componentes del impuesto (base, tarifa, formas de pago y exenciones) se administran por las autoridades responsables. Por su parte, el enfoque cultural, sugiere razones idiosincráticas o de costumbre frente al compromiso de los contribuyentes a pagar impuestos. Por su parte, la visión asociada al conflicto señala que la baja tributación es resultado del contexto de conflicto que se experimenta de manera heterogénea en el país, mientras que el enfoque que relaciona el pago del impuesto a la propiedad con las instituciones regionales o locales plantea que la concentración del poder tiene efectos negativos sobre las políticas de definición de las tarifas y las posibilidades de recaudo del impuesto a la propiedad rural.

Frente a la visión administrativa, depende de la calidad de los componentes del impuesto para implementarlo de manera eficaz. Entre otras, la formación y actualización catastral -información básica y fundamental para el impuesto predial- depende de la capacidad de ingresos de los municipios. Los municipios, en muchas ocasiones, argumentan escasez de recursos para la ejecución de proyectos tendentes a la actualización catastral, como si se desconociera que un mecanismo

\footnotetext{
Semana (2003). Todos ponen. Noviembre de 2013.
} 
para lograr mayores recursos es este. Como mencionan algunos autores, pareciera que los municipios se encontraran a gusto con un recaudo basado en información obsoleta sin motivación aparente para mejorarlo, como se encuentra en Chemonics (2004), Iregui, Ramos y Saavedra (2001), Iregui, Melo y Ramos (2003 y 2005), Leibovich (2005) y Zapata (1991).

Por su parte, los estudios que asocian el pago del impuesto con la cultura, señalan que la cultura de los contribuyentes en Colombia sigue la lógica del no pago, situación común entre los propietarios de tierras (Echavarría, 2002; Thoumi, 1999). Este comportamiento se ve reforzado por la influencia de los grandes dueños de tierra con miras a conservar una baja tributación, así como tasas bajas y valores catastrales obsoletos a fin de mantener en el mínimo nivel la responsabilidad fiscal derivada de la propiedad.

Otros, como Penning (2003) y Pérez (2004), sugieren que el bajo nivel de pago del impuesto a la propiedad rural es resultado de la situación de conflicto armado en Colombia. Este argumento no puede pasarse por alto en un país con una larga tradición de conflicto. Sin embargo, dada la larga duración del conflicto armado en Colombia el argumento según el cual este afecta y agudiza el desempeño económico, entre otros, la tributación, es insuficiente y deja de lado otras caras del problema.

Por último, está el enfoque que aborda la relación entre instituciones regionales o locales, intereses particulares y el pago de impuestos a la propiedad. Los estudios de esta área sugieren que la conformación de instituciones de jure $e^{2}$ puede ser influenciada o afectada por poderes de facto ${ }^{3}$ a fin de definir el marco institucional para favorecer o castigar a ciertos grupos. A su vez, el horizonte de permanencia en el poder político puede también afectar el manejo de los impuestos. Vargas y Villaveces (2016) adoptan este enfoque para indagar la asociación entre la concentración del poder local en el ámbito político y económico, con el pago del impuesto a la propiedad, y concluyen que los grandes hacendados logran afectar los componentes del impuesto predial en presencia de concentración política, es decir, no solo por el hecho de tener grandes extensiones de tierra bajo su control sino a través de sus influencias en el ámbito local, ya sea en la alcaldía o en el Concejo Municipal.

2 Las instituciones de jure son instituciones formales que definen los acuerdos entre actores y los mecanismos formales para acceder al poder. Son aquellas que son aceptadas por la sociedad y están escritas.

3 Instituciones o poder de facto se refiere a los mecanismos por fuera de la institucionalidad formal o sin que se ajuste a la normatividad que usan actores para detentar el poder. El poder de facto puede ser la intimidación, la violencia o la captura del poder institucional por parte de medios no legales. 
En resumen, el estado del arte acerca de los impuestos sobre la propiedad rural en Colombia apunta al consenso generalizado de la falta de tributación rural resultado de los intereses de los grandes terratenientes y la idea de una cultura de evasión arraigada también en los dueños de la tierra. Por su parte, los estudios sobre predial en Colombia centran su atención en el análisis agregado, sin distinguir entre predial urbano y predial rural. Esta diferenciación es importante porque las tarifas varían según la vocación rural o urbana del predio.

Esta visión del impuesto a la propiedad rural en Colombia contrasta con la literatura académica según la cual el impuesto a la propiedad es un impuesto eficiente. Autores como Bird (2008); Bird y Slack (2004); Bird y Zolt (2003), Oates y Schwab (1997), Slack (2010) y Kitchen (2003) sugieren que este impuesto puede reducir las distorsiones económicas propias de los impuestos y, por ende, conducir a una tributación más eficiente. Esta visión acerca de la tributación óptima se complementa con la perspectiva administrativa de la tributación que sugiere que el impuesto a la propiedad tiene bondades derivadas del reconocimiento del contribuyente y la dificultad para evadir, además de la facilidad para administrarlo por sus cualidades como la base y la tarifa. Varios autores como World Bank (2008), Duff (2003), Brennan y Buchannan (2006), Kitchen (2003), Bird y Slack (2004), Tanzi (1995) y Oates y Schwab (1997) sugieren que el alcance y eficiencia del impuesto deriva, en la mayor parte, del diseño y combinación de base, formas de cobro, tarifas y exenciones

Según De Cesare (2010), el desempeño del impuesto a la propiedad en Colombia frente a los demás países de América Latina es bueno y representa alrededor del 0.6 $\%$ del PIB, con un incremento en 2 puntos desde principios de los 2000 (cifra aún baja en términos de los países de la OCDE que alcanza al 1.5\% del PIB). Este buen desempeño relativo, está sustentado en el componente urbano del impuesto a la propiedad, mas no en la dinámica del impuesto a la propiedad rural. Por su parte, Bird y Slack (2002) afirman que las reformas fiscales descentralizadas han tenido buen impacto en el predial total, sin mayor cambio en el recaudo y comportamiento del predial rural. Aun siendo un impuesto relevante, es necesario aclarar que el componente urbano es el de mayor participación (predial urbano o impuesto sobre la propiedad urbana) $)^{4}$.

Por su parte, los análisis sobre el impuesto a la propiedad han puesto especial atención en su alcance como mecanismo de recaudo. El DNP (2015) señala que el impuesto a la propiedad es un tributo que presenta una buena contribución a las

Según Bird and Slack (2004, p. 39) "property tax reform in Colombia has resulted in an increase in the value of the tax base and an increase in revenues derived from the property tax. Furthermore, the cadastre registry has been updated". 
finanzas municipales: pasó de representar 0.3 \% del PIB en 1990 a cerca de 0.7 \% a finales de la década del 2000. Mientras que para 2015 cerca de un tercio del recaudo total municipal está representado por el impuesto a la propiedad5.

En la literatura existe un importante grupo de trabajos que señala que el impuesto a la propiedad rural en Colombia tiene un desempeño mediocre y está afectado por los intereses locales, a pesar de que este impuesto tenga atributos que lo cataloguen como un impuesto eficiente para las finanzas locales. Vale la pena explorar las razones de su bajo nivel de contribución a las finanzas locales en el ámbito rural. Para esto, en este trabajo se explorará la hipótesis, según la cual las instituciones locales afectan el desempeño del impuesto a la propiedad rural en Colombia. Esto, sin desconocer la relevancia del aspecto administrativo y cultural, en este documento se aborda la relación entre variables institucionales locales para entender el desempeño del predial rural en Colombia.

En este documento se aborda el comportamiento del impuesto a la propiedad en distintos contextos institucionales locales, a partir de un esfuerzo por calcular los datos existentes para el componente rural del impuesto y a través de un análisis de su comportamiento estadístico respecto a variables institucionales locales en el período de 1998 a 2010.

Para esto, se calculan cinco variables sobre el impuesto a la propiedad rural: tarifa efectiva del predial rural, tarifa nominal del predial rural, recaudo del predial rural per cápita, avalúo catastral rural per cápita, años desde la última actualización y número de actualizaciones. A su vez, se calculan cuatro variables institucionales: concentración de la tierra, concentración política en las elecciones locales, eficiencia jurídica y captura de gobiernos locales por parte de actores ilegales. Este análisis permite evidenciar la afirmación presente en la literatura, según la cual los dueños de grandes extensiones de tierra están, en particular, interesados en afectar las decisiones respecto al impuesto a la propiedad rural.

Este análisis es una contribución a la literatura en la medida en que son pocos los trabajos que abordan la relación entre variables institucionales y el desempeño del impuesto a la propiedad rural. Se destaca el trabajo de Vargas y Villaveces (2016) que encuentra cómo en municipios donde coinciden la alta concentración política y la económica, el impuesto a la propiedad es inferior en recaudo y actualización. También es una contribución al análisis genérico del impuesto a la propiedad rural, al proporcionar datos que no han sido presentados, quizá por la ausencia de este

En términos del peso relativo, el impuesto a la propiedad representa aproximadamente el $37 \%$ de los ingresos tributarios de los municipios, siendo, en promedio, el más importante el impuesto de Industria y Comercio. 
tipo de datos en Colombia ${ }^{6}$ y que permiten concluir el comportamiento heterogéneo de las variables del impuesto a la propiedad rural según instituciones como la concentración de tierra, la concentración política y la presencia de actores al margen de la ley capaces de capturar el poder local.

El documento está organizado en cinco partes incluyendo esta introducción. En la sección 1 se aborda la teoría sobre instituciones políticas y la relación con la tributación. Luego se presenta la legislación del impuesto a la propiedad en Colombia. En la sección 3 se presentan los datos y el comportamiento del impuesto a la propiedad en Colombia asociado con las instituciones locales. Finalmente se concluye que existe un comportamiento heterogéneo del predial respecto a las variables institucionales observadas en el ámbito municipal.

\section{INSTITUCIONES LOCALES Y TRIBUTACIÓN}

Siguiendo el análisis de Acemoglu, Johnson y Robinson (2005), el desempeño económico depende de las instituciones económicas definidas por el poder de jure, que es, a su vez, establecido por las instituciones políticas. En otras palabras, la elección institucional inicial es el resultado de la selección de las instituciones políticas que son, a su vez, una expresión del poder político en la sociedad. Las instituciones económicas y las instituciones políticas son endógenas, determinadas por la sociedad o por un segmento de ella.

Los aportes de la economía institucional permiten entender la interacción de distintos intereses y reglas de juego en el desempeño económico de una sociedad. Como señala North (1990), hay un amplio consenso sobre el peso de las instituciones o limitaciones en el desempeño económico. No obstante, algunos autores señalan la necesidad de entender por qué se consolidan y mantienen ciertas instituciones aun cuando han mostrado ser débiles o no han generado los resultados esperados. En esta medida, los aportes de Acemoglu, Johnson y Robinson (2005), proporcionan un marco teórico para entender la persistencia de algunas instituciones en ciertas sociedades.

Entonces, el interrogante no es exclusivo acerca del desempeño económico de unas sociedades dadas ciertas instituciones, sino también de cómo y por qué se llega a la consolidación de tales instituciones. Acemoglu, Johnson y Robinson

6 En Colombia, existe una deficiencia de la información agregada acerca del recaudo y desempeño del predial rural en Colombia. Es decir, la falta de información sobre tasas impositivas y el tamaño del recaudo por año. No existe en el país ninguna entidad nacional o centralizada que recoja estos datos. De ahí la dificultad para hacer análisis y el enorme obstáculo para los investigadores interesados en acercarse al problema de la tributación de la tierra rural. 
(2005) sugieren que el fundamento inherente a cualquier definición institucional es el poder político, que puede ser tanto de jure como de facto. En definitiva, contar con el poder político garantiza el poder para definir las instituciones económicas que se implementarán en una sociedad. De esta manera, la interacción social está en buena medida determinada por la distribución del poder político en una sociedad.

Tal como mencionan Acemoglu, Johnson y Robinson (2005), las instituciones políticas están definidas por quien acceda al poder de jure y, alteradas por quienes tengan el poder de facto que, a su vez, está en función de la distribución de recursos en una sociedad. Una vez las instituciones políticas han sido elegidas, se definirán las instituciones económicas que a su turno moldearán el desempeño económico.

Los impuestos sobre la tierra son un sistema que responde a intereses económicos. Se grava la tierra por la necesidad de recaudar ingresos, por el reconocimiento de ciertos derechos de propiedad y por la posibilidad de incentivar actividades económicas. No obstante, el sistema de impuestos sobre la tierra no se define en el vacío. Son las instituciones políticas las que delimitan el comportamiento de los impuestos, su alcance y su magnitud. De ahí que, antes que entender cuánto se recauda, se vuelve fundamental entender por qué ciertas instituciones políticas son más proclives a un bajo recaudo que otras.

Un primer asunto es, si puede decirse, que el bajo desempeño del impuesto es un acto de corrupción. Según Aidt (2003, p. 633) existen tres condiciones que permiten que la corrupción surja y persista: poder discrecional (el poder del servidor público le permite diseñar o administrar las regulaciones o políticas de manera discrecional); la existencia de rentas económicas (el poder discrecional debe permitir la extracción o creación de rentas con fines extractivos) y por último, una institucionalidad débil que genere incentivos a los servidores para la extracción de rentas. En este sentido, actuaciones que no busquen una buena administración del sistema tributario serían actos de corrupción.

Para de Della Porta y Vannucci (2005, p. 5), la corrupción estaría arraigada en la cultura. Para los autores, las sociedades con principios personalistas de parentesco, comunidad y clientelismo usan la corrupción en las relaciones con el Estado, aun después de procesos de democratización de los que se esperaría no prevalecieran estos comportamientos. Los autores sugieren que el patrimonialismo ha logrado adaptarse con buenos resultados al marco institucional de la democracia.

Aspectos como la concentración de la tierra evidencian el poder de facto que puede influenciar la política local, como concluyen Profeta y Scabrosetti (2007) y Acemoglu, Ticchi y Vindigni (2006). Además, como afirman Sokoloff y Zolt (2007), la 
presencia de una gran desigualdad económica (distribución de la tierra) se asocia con baja imposición fiscal en términos de tasas, recaudo y valores catastrales.

Por su parte, un ambiente político de baja competencia electoral en el ámbito local puede reflejar que el gobierno local sea más susceptible de ser capturado por las élites locales (que incluye las élites terratenientes), lo que produce una distorsión en la política pública y en la política tributaria, tal como señalan Bordignon, Cergiglia y Revelli (2002) y Acemoglu, Johnson y Robinson (2005).

Para Acemoglu y Robinson (2008) el uso de poder político de facto puede reflejar cómo los grupos de las élites locales están dispuestos a utilizar mecanismos informales a fin de afectar la toma de decisiones en la configuración institucional de jure, lo que exacerba las instituciones formales con el fin de establecer y mantener instituciones ineficientes que garanticen el interés particular; en el caso del impuesto, quizá para mantener bajos los impuestos sobre la tierra.

En términos de capacidad judicial, la fortaleza o debilidad del sistema de justicia se asocia con la capacidad de hacer cumplir la ley y establecer sanciones cuando se incumple. Autores como Scholz (1998), Fjeldstad (2004), Müller y Zouridis (2012) y Uslaner (2003) subrayan que un ambiente judicial débil reduce la capacidad de recaudo fiscal e incentiva la evasión tributaria. En el caso del predial rural, se esperaría algún tipo de comportamiento negativo en ambientes de baja capacidad del sistema de justicia.

Los aspectos administrativos y técnicos de los impuestos son importantes para comprender el rendimiento de impuestos. Políticas hacia una mejor gestión de los impuestos pueden tener resultados importantes en términos de recaudo y cumplimiento. Sin embargo, al evaluar las razones del desempeño fiscal, el punto de vista administrativo y técnico es insuficiente y no puede capturar la complejidad detrás de la tributación; no solo como un instrumento de política, sino también como una herramienta importante de la relación entre los ciudadanos y el Estado que expresa los intereses particulares y tendencias históricas de una sociedad.

Para Feld y Kirchgässner (2001), los gobiernos locales, bajo esquemas de democracia directa, están más capacitados para organizar la toma de decisiones en el ámbito local. Si bien los autores muestran cómo los gobiernos locales logran administrar mejor los impuestos a su cargo, dejan abierta la interpretación de que una democracia con vicios puede administrar el impuesto a favor de intereses particulares.

Los impuestos, vistos como una cuestión de la capacidad administrativa del Estado para recaudar, dejan de lado el poder y la tensión de los intereses privados 
innatos a la tributación. Como asevera Dijohn (2006), explicar el problema tributario en la dimensión administrativa es asumir que la capacidad del Estado es estática, lo que significa que el Estado no cambia sus preferencias, que no hay grupos de intereses que presionen al gobierno y que el poder de negociación entre gobernantes y ciudadanos no presenta ninguna dificultad, algo muy difícil de creer.

Por otra parte, en la perspectiva de la economía institucional se reconoce que la fiscalidad también revela los intereses de las élites, las maniobras de los políticos y otros acuerdos que pueden afectar el pago o el recaudo del impuesto. Como manifestó Keynes (citado por Bird, 2008, p. 3):

[...] la política fiscal en todas partes está formada no sólo por las ideas y los intereses creados, sino también por las cambiantes condiciones económicas, administrativas, las posibilidades tecnológicas y, sobre todo, las instituciones políticas dentro de las cuales esos factores entran en juego -ideas, intereses e instituciones-para determinar la política fiscal.

Por lo anterior, los acuerdos políticos y las normas, junto con las leyes y reglamentos en la sociedad y la distribución del poder pueden dar respuestas para entender la elección de un tipo de impuesto y su desempeño. El análisis a partir de la economía política del impuesto predial en Colombia exige ver las decisiones tanto políticas como económicas que subyacen a tal. En el ámbito político, es necesario entender qué lleva a mantener un sistema torpe e ineficiente de recaudo del impuesto sobre la propiedad.

El análisis institucional presenta cómo las instituciones políticas son determinantes en la configuración de las reglas de juego. Las instituciones políticas definen los mecanismos para alcanzar el poder que refleja los distintos intereses detrás del alcance de la toma de decisión de los gobernantes. En otras palabras, los acuerdos políticos definen el alcance del poder que los gobernantes pueden luego ejercer y modificar. Por otro lado, las instituciones políticas establecen la regla del juego económico, fuente fundamental de poder económico de los actores existentes. Por lo tanto, controlar las instituciones políticas es una oportunidad para mantener el poder político y económico: el poder político, mediante la definición de incentivos para permanecer en el poder, y el poder económico mediante la definición de incentivos para tener mayores ventajas en el terreno económico.

Este enfoque institucionalista permite rastrear las razones subyacentes a la definición y desempeño del impuesto predial rural en Colombia, no solo en términos del logro definitivo del recaudo impositivo y el comportamiento de las tasas sino también a partir de razones más allá de su diseño; es decir, no como el resultado llano de una decisión administrativa, sino como un resultado complejo de fuerzas 
políticas, disposiciones económicas e intereses públicos y particulares que subyacen al sistema de tributación de la propiedad rural.

\section{LEGISLACIÓN DEL IMPUESTO A LA PROPIEDAD EN COLOMBIA}

La implementación del predial rural en Colombia respondió a la idea común de inducir a los dueños de la tierra a un uso productivo de la misma y, a través de estos recursos, financiar en parte el gobierno local. De igual forma, el impuesto sobre la tierra es una respuesta a la distribución desigual de la propiedad, que exige del Estado una posición de equidad al definir impuestos progresivos a los dueños.

En Colombia, el impuesto predial tiene antecedentes en el siglo XIX, cuando los gobiernos liberales decidieron desmontar las instituciones coloniales y establecer, entre otras, impuestos progresivos, más afines con los criterios de libertad e igualdad que defendían. En 1850 con la Ley del 20 de abril, se crea el impuesto predial que debía ser administrado por las Provincias (gobiernos locales). Sin embargo, esta iniciativa no fue exitosa pues este impuesto se eliminó.

A mediados del siglo veinte, vuelve la discusión sobre la contribución de la tierra a las finanzas. En 1954, durante la dictadura, el general Gustavo Rojas Pinilla estableció que los dueños de tierras debían declarar el valor real de sus tierras bajo la amenaza de que el Gobierno se reservaría el derecho de comprar tierras al valor declarado. Esto buscaba establecer una relación consistente entre el avalúo de la tierra y el mercado de tierras; no obstante, los grandes latifundistas sabían de la incapacidad del Gobierno para comprar grandes cantidades de tierra que debía declarase; por tanto, esta iniciativa no logró el propósito de afectar el valor de la tierra. Esta medida fue intentada sin éxito por el Gobierno en $1961^{7}$.

Por esta misma época, dos informes del Banco Mundial hicieron recomendaciones explícitas sobre la necesidad de establecer un impuesto predial. En el informe de Currie (1952), The Basis of a Development Program for Colombia y en el informe de Taylor y Richman (1965) titulado Fiscal Survey of Colombia, se señala la importancia de implementar un impuesto progresivo respecto al valor de la tierra, como mecanismo para desincentivar la concentración de la tierra y el uso especulativo de la misma, en época de inflación (Palacios; 2002, p. 568). En la misma perspectiva, el profesor Richard Musgrave lideró la comisión para la reforma fiscal en los años sesenta que, entre otras, recomendó la definición del impuesto predial para financiar y mejorar la inversión en bienes públicos.

Se buscaba con esta, un decreto de auto avalúo que establecía que todos los propietarios de propiedades mayores a 100 hectáreas o con un valor catastral superior a 20.000 pesos, debían establecer su propio avalúo cada dos años. 
Estos intentos de definir un impuesto predial solo lograrían concretarse en los años ochenta en conjunto con la iniciativa de descentralización administrativa liderada por el gobierno de Belisario Betancourt. La Ley 14 de 1983 crea el impuesto predial, como ingreso local llamado a fortalecer las finanzas locales. En términos del impuesto predial, esta ley estableció los instrumentos y mecanismos para el recaudo. El avalúo catastral sería la base del impuesto. Así, la formación y actualización catastral serían herramientas determinantes para el buen funcionamiento del impuesto. Por su parte, la tarifa es definida por el Concejo Municipal ${ }^{8}$, de manera progresiva con base en el rango establecido entre el 4 y el 12 por mil.

En 1990 se toma la decisión de unificar varios impuestos en el Impuesto Predial Unificado (IPU). El Congreso de la República define el IPU como la unificación de los siguientes impuestos: impuesto predial, impuesto de parques y arborización, impuesto de estratificación socio-económica y sobretasa de levantamiento catastral, con el fin de reducir la complejidad asociada a los impuestos que gravaban la propiedad. No hubo cambios respecto a la jurisdicción del impuesto, la base impositiva y la responsabilidad del Concejo Municipal en la definición de la tarifa. Hubo reformas respecto al rango de la tarifa que incrementa el límite superior a 16 por mil y el aumento del avalúo catastral anual entre el 70 y $100 \%$ del incremento anual del índice de precios al consumidor. Esta ley también definió el 10 \% del recaudo del impuesto predial con destinación específica a programas de vivienda de interés social y para crear un fondo para las actualizaciones catastrales (Ley 44, 1990) ${ }^{9}$.

En 2011, el Congreso de la República, modificó el límite inferior del rango de tarifa del Impuesto Predial Unificado del 1 al 5 por mil. El rango actual de tarifas es entre el 5 y 16 por mil del respectivo avalúo. También estableció los parámetros de la progresividad del impuesto a partir de los estratos socioeconómicos, el uso del suelo en el sector urbano, la antigüedad de la formación o actualización del catastro, el rango de área y el avalúo catastral. También definió que para la propiedad rural con destino económico agropecuario en estratos 1 al 3 y con un valor inferior a 135 salarios mínimos mensuales legales vigentes, se establecerá la tarifa entre 1 y 16 por mil, como se observa en la tabla 1 (Ley 1450 de 2011) ${ }^{10}$.

8 Son corporaciones administrativas del nivel municipal encargadas de ejercer el control político de la Administración municipal y el estudio de los proyectos de acuerdo. Entre otras funciones, reglamenta el uso del suelo y determina las tarifas de los impuestos del orden municipal, entre estos, el predial.

9 Congreso de la República, Ley 44 de 1990 del 18 de diciembre de 1990, por la cual se dictan normas sobre catastro e impuestos sobre la propiedad raíz, se dictan otras disposiciones de carácter tributario, y se conceden unas facultades extraordinarias.

10 Congreso de la República, Ley 1450 de 2011 del 16 de junio de 2011, por la cual se expide el Plan Nacional de Desarrollo 2010-2014. 
Tabla 1. Factores que definen la tarifa del impuesto predial

\begin{tabular}{|c|c|c|c|c|}
\hline & \multicolumn{2}{|c|}{ Urbano } & \multicolumn{2}{|c|}{ Rural } \\
\hline $\begin{array}{l}\text { Tipo de } \\
\text { predio }\end{array}$ & $\begin{array}{l}\text { Predios urbanos, } \\
\text { que se encuentran } \\
\text { dentro del perí- } \\
\text { metro urbano del } \\
\text { municipio }\end{array}$ & $\begin{array}{l}\text { - Terrenos urba- } \\
\text { nizados no edifi- } \\
\text { cados } \\
\text { - Terrenos urba- } \\
\text { nizables no ur- } \\
\text { banizados }\end{array}$ & $\begin{array}{l}\text { Predios rurales, } \\
\text { los cuales se en- } \\
\text { cuentran fuera del } \\
\text { perímetro urbano } \\
\text { del municipio }\end{array}$ & $\begin{array}{l}\text { Pequeña propie- } \\
\text { dad rural destina- } \\
\text { da a producción } \\
\text { agrícola }\end{array}$ \\
\hline Base impositiva & Avalúo catastral & Avalúo catastral & Avalúo catastral & Avalúo catastral \\
\hline $\begin{array}{l}\text { Tarifa o } \\
\text { alícuota }\end{array}$ & $\begin{array}{l}\text { Tarifa progresiva } \\
\text { por: } \\
\text { - Estrato } \\
\text { - Uso del suelo } \\
\text { - Avalúo } \\
\text { - Antigüedad de } \\
\text { la formación ca- } \\
\text { tastral }\end{array}$ & $\begin{array}{l}\text { Tarifa superior que } \\
\text { no exceda } 33 \text { por } \\
\text { mil }\end{array}$ & $\begin{array}{l}\text { Tarifa progresiva } \\
\text { por: } \\
\text { - Rango de tama- } \\
\text { ño del predio } \\
\text { - Uso del suelo }\end{array}$ & $\begin{array}{l}\text { Tarifa mínima que } \\
\text { establezca el res- } \\
\text { pectivo Concejo }\end{array}$ \\
\hline
\end{tabular}

Fuente: Ley 1450 de 2011.

Como elemento fundamental del IPU, el catastro también ha tenido su desempeño y sus cambios. Según Offstein (2005) señala, la creación de los registros catastrales incluye tres procesos: de recolección de la información física de los predios, luego la actualización y, por último, la conservación que reconoce las mutaciones o cambios de un predio ${ }^{11}$. Este proceso está, a su vez, vinculado con el incremento anual que debe hacerse a los avalúos catastrales conforme a la inflación causada. En Colombia, según el DNP, el nivel de desactualización del total de los avalúos catastrales de los predios rurales del país es del $56 \%$. De estos, corresponde el levantamiento al Instituto Geográfico Agustín Codazzi (IGAC) de 10.368.422 predios, de los cuales 3.547.859 son rurales y 2.039.767 están desactualizados. A esto se suma que existen municipios con una desactualización catastral de más de 40 años (DNP, 2015). La persistencia de un catastro desactualizado tiene implicaciones sobre los valores catastrales y, por ende, en el recaudo del IPU, además de incentivar la concentración de tierra, el bajo uso agropecuario y la especulación con la tierra.

Es decir, el IPU no solo depende de la voluntad en definir de manera progresiva el impuesto sino también en crear y mantener las herramientas para su implementación, en especial, el catastro. Con miras a enfrentar esta situación, el Congreso de la República establece la política de contar con un catastro que tendrá múltiples

11 Estos procesos son llevados a cabo en su gran mayoría por el Instituto Geográfico Agustín Codazzi (75\% del catastro nacional) y los catastros descentralizados de Bogotá, Medellín y Cali en ciudades, y de Antioquia como departamento. 
propósitos más allá de los fiscales. La razón que lleva a esta visión del catastro es la necesidad de responder a la información que sustenta la tributación local (predial) y brindar información veraz que apoye los procesos de gestión de tierra y la política agraria, determinante en los procesos de fortalecimiento de la capacidad local (Ley 1753 de 2015$)^{12}$.

Según Sánchez y España (2013), en promedio, los municipios actualizan su catastro después de ocho años o más, lo cual lleva a que mantengan un catastro desactualizado al menos por una década, y ello repercute en el bajo recaudo del predial en Colombia; sin embargo, varios municipios mantienen rezagos que superaran los 50 años, es decir, no han realizado ninguna actualización desde que formaron su catastro. Además, señalan que el esfuerzo de aumentar los avalúos año a año según la inflación no potencia el recaudo, dada la brecha entre los avalúos y los precios de mercado de la tierra.

Este recuento de la legislación del impuesto muestra varios temas que no son simples hechos legislativos sino que muestran las tensiones e intereses detrás del impuesto predial, en especial, aquel que grava la tierra rural. En particular, se observa el rezago histórico para implementar un impuesto sobre la propiedad, a pesar de la relevancia que en distintos momentos se le dio a este impuesto para las finanzas locales. Solo hasta la década del ochenta del siglo veinte se logra definir e implementar este impuesto como uno de los pilares de las finanzas locales. Es decir, nuestra historia del impuesto predial es bastante corta, cuenta un poco más de tres décadas. A esto, se suma que este impuesto comenzó a funcionar sin mayor información catastral que lo sustentara' ${ }^{13}$. Esta situación puede explicar la ausencia de información catastral y la dificultad para lograr una actualización catastral real, como una fotografía reciente de la propiedad del país. No obstante, se observa tanto en la ley como en la dinámica de actualización el rezago en particular de la propiedad rural. Esto hace relevante preguntarse por las razones que explican

12 En el artículo 104 de la Ley 1753 de 2015 se señala que: "Catastro multipropósito. Se promoverá la implementación del catastro nacional con enfoque multipropósito, entendido como aquel que dispone información predial para contribuir a la seguridad jurídica del derecho de propiedad inmueble, al fortalecimiento de los fiscos locales, al ordenamiento territorial y la planeación social y económica. El Gobierno nacional, a través del Instituto Geográfico Agustín Codazzi (IGAC) con el apoyo de los catastros descentralizados, podrá realizar las actividades necesarias para la formación y actualización catastral de manera gradual e integral, con fines adicionales a los fiscales señalados en la Ley 14 de 1983, logrando plena coherencia entre el catastro y el registro, mediante levantamientos por barrido y predial masivo, en los municipios y/o zonas priorizadas con el Departamento Administrativo Nacional de Estadística, el Departamento Nacional de Planeación, el Ministerio de Agricultura y Desarrollo Rural y el Ministerio de Ambiente y Desarrollo Sostenible, conforme con la metodología definida para el efecto". Congreso de la República, 9 de junio de 2015, Ley 1753, por la cual se expide el Plan Nacional de Desarrollo 2014-2018: "Todos por un nuevo país".

13 Si bien Catastro Nacional existe desde 1935 como dependencia del Estado Mayor General del Ejército, luego como Instituto Geográfico Agustín Codazzi en los años cincuenta, su vocación estuvo más centrada en la cartografía que en el apoyo y misión catastral. 
este rezago, quizá por simple manejo de las herramientas administrativas del IPU o, también, por razones de economía política que permite beneficiar a grupos particulares por la forma en que se implementa y administra el impuesto por parte de las autoridades encargadas.

La legislación vincula dos autoridades locales en el manejo y funcionamiento del impuesto predial: de un lado, la Alcaldía, que define las formas de recaudo y la iniciativa de actualizar el catastro. De otro lado, el Concejo Municipal define la tarifa que debe estar en los rangos definidos por el Congreso de la República y debe velar por la progresividad, según tamaño, valor y uso.

Se infiere del análisis de las leyes sobre el impuesto predial y de los documentos Conpes sobre catastro que hay debilidades en la implementación del impuesto tanto por el esfuerzo de actualización de avalúos catastrales como por la competencia de dos órganos de gobierno local (alcaldías y concejos), con intereses que pueden no estar alienados. Así, la legislación puede ser punto de partida también para el análisis de economía política, dado que señala los poderes locales y las necesidades administrativas para el adecuado funcionamiento del impuesto.

\section{COMPORTAMIENTO DEL IMPUESTO A LA PROPIEDAD RURAL BAJO DISTINTOS ENTORNOS INSTITUCIONALES LOCALES}

El impuesto a la propiedad rural en Colombia es un impuesto cuya definición se da en el ámbito sub-nacional, el cual ha sido descrito como influenciado por las elites locales, que son grupos con intereses en la propiedad rural (las elites tradicionales y nuevas han logrado capturar la política local aún bajo procesos de descentralización política). Por lo tanto, la configuración local de la institucionalidad política en Colombia es un escenario interesante para entender el comportamiento del impuesto predial.

Se exploran estadísticas del comportamiento del predial rural a la luz de variables políticas que pueden dar cuenta de pautas o diferencias en grupos de municipios. Para esto, se analizan las instituciones locales como la concentración del poder político en la conformación del concejo municipal y la alcaldía, la eficiencia en la justicia, la concentración de la tierra como proxy del potencial poder de la élite terrateniente y la captura del poder local por parte de actores al margen de la ley. Estos resultados contribuyen a entender por qué el recaudo del impuesto predial rural y las tarifas son, en apariencia, bajas en Colombia y cómo las instituciones políticas locales afectan esta situación.

Es importante aclarar que en Colombia no existe información desagregada sobre el recaudo del predial de predios urbanos y de predios rurales. Entonces, indagar 
sobre el impuesto "predial rural" implica hacer un cálculo o una aproximación. A su vez, indagar sobre la tarifa nominal del impuesto predial exige revisar la información en los municipios, a partir de la exploración los acuerdos del Concejo Municipal, documentos que contienen las decisiones locales relativas, entre otros, a las tarifas del impuesto predial.

\subsection{Datos y cálculo de variables del estudio ${ }^{14}$}

Para fines de este documento, se calcularon las variables que utilizan para evaluar la evolución del predial rural en Colombia: i) tarifa efectiva del predial rural; ii) recaudo del predial rural; iii) recaudo del predial rural per cápita; iv) tarifa nominal del predial rural; v) avalúo catastral de los predios rurales per cápita y vi) de rezago en la actualización catastral.

Se obtuvo información para 980 municipios de los 1.120 que tiene Colombia. Se excluye información de las oficinas de catastro independientes que son Medellín, Bogotá, Cali y el Departamento de Antioquia ${ }^{15}$. Los datos obtenidos comprenden información del período 1998-2010.

La información de las variables es tanto académica como oficial. Las fuentes oficiales son el DNP, el IGAC, el DANE, la Registraduría Nacional del Estado Civil y el Consejo Superior de la Judicatura, mientras que la única fuente académica es la información de López (2010).

Las seis variables del desempeño del impuesto predial rural y urbano se calcularon con base en la información del DNP que registra el recaudo total por concepto del predial para cada municipio año a año y teniendo en cuenta otras variables como los avalúos catastrales del IGAC y los datos poblacionales del DANE.

La tarifa efectiva del predial rural (TEPR) para el municipio $i$ en el período $t$ se calculó como la relación entre el recaudo del predial rural (RPR) y el avalúo catastral rural (ACR) por mil. La tarifa efectiva del predial rural se refiere al recaudo real del impuesto respecto al avalúo de los predios sujetos de impuesto, reflejando la tarifa que efectivamente se aplica sobre la propiedad. Esta variable permite entender dos temas: de un lado, el alcance del recaudo, y del otro, la brecha de la tarifa efectiva respecto a la nominal.

\footnotetext{
14 Los investigadores interesados en el tema pueden solicitar las variables construidas y la información utilizada en este documento al correo electrónico: mjvillaveces@unal.edu.co.

15 Si bien la falta de información de Antioquia puede generar un sesgo estadístico, la muestra es lo suficientemente grande para ser estadísticamente significativa pues representa el $86 \%$ de los municipios de Colombia.
} 


$$
\boldsymbol{T E P R}_{i t}=\left(\boldsymbol{R P R _ { i t }} / \boldsymbol{A C R _ { i t }}\right) * 1.000
$$

Donde el recaudo del predial rural (RPR) es estimado teniendo en cuenta el recaudo total urbano y rural (RPT) multiplicado por el índice de ruralidad (IR).

$$
\boldsymbol{R P R} \boldsymbol{R}_{i t}=\boldsymbol{R P T} T_{i t} * I R_{i t}
$$

El recaudo del predial per cápita (RPper) tiene en cuenta el recaudo total sobre la población total (PT) en el municipio ${ }_{i}$, en el año ${ }_{t}$

$$
\boldsymbol{R P p e r}_{i t}=\boldsymbol{R P T _ { i t }} / \boldsymbol{P T} T_{i t}
$$

La tarifa nominal del predial rural (TNPR) se calculó como promedio de las tarifas nominales del predial rural en el municipio (prom. TNPR). Esta información se obtuvo a partir de los acuerdos municipales según los cuales se expiden los estatutos de rentas por parte de los concejos municipales. Estos datos se pudieron obtener para 740 municipios. La tarifa nominal del predial rural permite ver la definición de la tarifa promedio respecto al rango definido para predios rurales según la ley, como un indicador de progresividad o de relativa homogeneidad de la tarifa.

$$
\operatorname{TNPR}_{i t}=\operatorname{prom} .\left(T N P R_{i t}\right)
$$

El avalúo catastral de los predios rurales per cápita (ACRper) es el avalúo catastral de las propiedades rurales (ACR) frente a la población rural (PR) en cada municipio. Esta información se obtuvo del IGAC.

$$
A C \text { Rper }_{i t}=A C R_{i t} / P_{i t}
$$

Finalmente, la variable de rezago en la actualización catastral (RAC) se calcula como la diferencia entre el año de la última actualización (AUA) y el año de la penúltima actualización (APA), utilizando la información del IGAC sobre los años de actualización del catastro y el trabajo de Sánchez y España (2013).

$$
\boldsymbol{R A C} \boldsymbol{C}_{i t}=\boldsymbol{A U} \boldsymbol{A}_{i t} / \boldsymbol{A P A _ { i t }}
$$

Las variables institucionales se calcularon teniendo en cuenta información oficial e información académica. Para la concentración de la tierra, se tomó la base de datos del Centro de Estudios sobre Desarrollo Económico (CEDE) de la Universidad de los Andes $^{16}$, que calculó el índice de concentración de la propiedad rural registrada en

Las bases de datos del CEDE están disponibles, previa inscripción, en el siguiente link: https://datoscede. uniandes.edu.co/. 
el IGAC para el período de 2000 a 2009. Esta variable toma valores entre 0 y 100, donde a mayor valor, mayor concentración de la propiedad de la tierra.

La variable que mide la concentración política (CP) tiene información para 4 elecciones locales desde 1998 para el concejo y la alcaldía. Esta variable busca capturar la concentración en la composición del concejo municipal según el partido mayoritario y la afinidad con el alcalde en términos partidistas. Esta información viene de la Registraduría Nacional del Estado Civil. Está calculada como número de concejales electos del mismo partido del Alcalde (NCPA) en relación con el total de concejales del municipio (TCM). La variable toma valores de 0 a 100 donde una cifra cercana a cero indica que todos los miembros del concejo municipal son de partidos diferentes al del alcalde y 100 donde hay un único partido hegemónico en el concejo y la alcaldía del municipio.

$$
\boldsymbol{C P}_{i t}=N C P A_{i t} / \mathrm{TCM}_{i t}
$$

La variable que mide eficiencia del sistema judicial (ESJ) se calcula con base en la información del Consejo Superior de la Judicatura para el período de 2003 a 2009. La variable se calcula como la relación entre los casos finalizados (CF) y el total de casos del sistema judicial del municipio (TCSI). Esta variable toma valores de 0 a 1 , donde 1 es eficiencia del $100 \%$ en la justicia y 0 la ineficiencia total. La información incluye los procesos exitosos, las demoras y los casos sin castigos judiciales lo que permite calcular la proporción de casos finalizados del sistema judicial en el municipio $_{i}$, en el año $t$, así:

$$
\boldsymbol{E S J}_{i t}=\boldsymbol{C F}_{i t} / \boldsymbol{T C S J}_{i t}
$$

Por último, la variable que mide la evidencia de captura del poder local por parte de actores al margen de la ley se calcula con base en la información de López (2010), sobre políticos locales con relaciones con paramilitares, guerrilla o narcotraficantes. Según el informe, hay vínculos evidentes de personas (políticos investigados) para 305 municipios para el período entre 2000 y 2008. En este caso, se define una variable dummy para los vínculos con paramilitares, otra con guerrilleros y otra con narcotraficantes.

También se incluyen variables descriptivas de la conformación de los municipios y que no son directamente variables políticas, como el área de los municipios, el nivel de ruralidad y la informalidad de la tierra ${ }^{17}$. Estas variables permiten también

La informalidad de la tierra es medida por el IGAC y muestra la proporción de predios con informalidad en la propiedad de la tierra, es decir, con sin registro en la oficina de registros públicos del municipio. 
complementar el análisis para ver si el comportamiento del impuesto del predial rural está afectado por el área del municipio (a mayor área, más propiedades y quizá más recaudo), el índice de ruralidad (a mayor ruralidad, puede haber más participación de predios rurales en el recaudo y por ende mayor recaudo) y la informalidad que sugiere que los niveles altos de informalidad de la propiedad de la tierra pueden reducir el recaudo del predial rural.

\subsection{Comportamiento del predial rural según variables institucionales locales}

El análisis descriptivo se basa en las variables institucionales distribuidas en cuarti$l^{1} s^{18}$, a fin de ver si se observa algún comportamiento diferenciado en el desempeño del impuesto predial.

De acuerdo con el análisis teórico, la relación entre instituciones políticas y desempeño del impuesto predial puede favorecer o frenar el buen desempeño económico. En concreto, los acuerdos políticos más competitivos que, según la literatura son más afines a la rendición de cuentas (Besley y Preston, 2002 y Besley, Persson y Sturm, 2005), se pueden asociar con un buen desempeño económico (tributario), mientras que los que promueven la exclusión podrían empeorar el resultado.

La evidencia estadística para el total de la muestra (980 municipios), da cuenta de que la tarifa efectiva de predial rural está 1,52 puntos por encima de la agregada (rural y urbana). También se observa que el número de actualizaciones catastrales que se han realizado en el período es de un año y medio, en promedio, (algo por debajo de lo esperado para el período que deberían ser, al menos 5 actualizaciones si se cumple la ley que señala que la actualización catastral debe hacerse cada 5 años). Además, se observa un promedio de 6.69 años de brecha entre actualizaciones catastrales, mayor a los cinco años que define la ley (tabla 2).

Tabla 2. Estadísticas descriptivas de variables de desempeño del predial rural, 1998-2010

\begin{tabular}{|l|c|c|}
\hline \multicolumn{1}{|c|}{ Variables del predial rural } & Media & $\begin{array}{c}\text { Desviación } \\
\text { estándar }\end{array}$ \\
\hline Tarifa nominal predial rural (\%) & 5,72 & 2,37 \\
\hline Tasa efectiva predial rural (\%) & 6,50 & 15,42 \\
\hline Tarifa efectiva predial (rural y urbano) (\%) & 5,46 & 4,01 \\
\hline Recaudo Predial rural per cápita (miles de pesos) & 22,65 & 28,37 \\
\hline
\end{tabular}

18 El primer cuartil concentra el $25 \%$ más bajo de la variable de interés, mientras el cuartil cuatro concentra el 25 \% más alto de la variable. Se presenta la información de los cuatro cuartiles. 
Marta Juanita Villaveces Niño

\begin{tabular}{|l|c|c|}
\hline \multicolumn{1}{|c|}{ Variables del predial rural } & Media & $\begin{array}{c}\text { Desviación } \\
\text { estándar }\end{array}$ \\
\hline Avalúo catastral rural per cápita (millones de pesos de 2008) & 5,47 & 8,60 \\
\hline Número de veces que se ha realizado actualizaciones catastrales rurales. & 1,65 & 0,49 \\
\hline Años desde la última actualización catastral (rezago catastral) & 6,69 & 5,30 \\
\hline
\end{tabular}

Fuente: cálculos propios basado en datos del DNP para recaudo tributario municipal, datos de Acuerdos Municipales para tarifa nominal y datos del IGAC para avalúo de los predios rurales y actualización catastral.

Tabla 3. Estadísticas descriptivas de variables institucionales en el ámbito local, 1998-2010

\begin{tabular}{|l|c|c|}
\hline \multicolumn{1}{|c|}{ Variables políticas y económicas locales } & Media & $\begin{array}{c}\text { Desviación } \\
\text { estándar }\end{array}$ \\
\hline Coeficiente de Gini de la tierra & 69,72 & 10,10 \\
\hline Concentración política & 39,78 & 25,44 \\
\hline Eficiencia en la justicia & 0,84 & 0,64 \\
\hline Captura de poder local por actores al margen de la ley (dummy) & 0,06 & 0,26 \\
\hline
\end{tabular}

Fuente: cálculos propios basado en datos del IGAC para gini de la tierra, Registraduría Nacional del Estado Civil para competencia electoral, Consejo Superior de la Judicatura para Eficiencia en la Justicia y López (2010) para captura del poder local.

Respecto a las variables institucionales (tabla 3), se observa que en promedio, el coeficiente de Gini de la tierra es de casi 0,70, lo que implica una alta concentración de la propiedad. La concentración política, por su parte, es cercana al 40 \% lo cual indicaría que en promedio, los alcaldes cuentan con una proporción importante de apoyo partidista en el Concejo sin representar una mayoría. La eficiencia en la justicia muestra también un coeficiente de 0,84 , que implica un sistema de respuesta que parece eficiente frente a los procesos demandados a la justicia y, por último, la captura del poder local por actores ilegales, casi inexistente.

La tabla 4 muestra el comportamiento de las variables del predial rural según el área del municipio. Se observa que a mayor área del municipio, menor el recaudo y mayores las tarifas efectivas. Esto revela que municipios pequeños quizá son más urbanos, de forma tal que se logra una representación mayor de la propiedad urbana en el recaudo. Por su parte, a mayor tamaño, la ruralidad incrementa por lo cual se aumenta la tarifa efectiva del predial rural. También es interesante el aumento de rezago catastral a medida que los municipios tienen un área mayor. Esto puede explicarse, dado que los municipios con grandes extensiones están ubicados en el sur occidente del país, antes conocido como los territorios nacionales, con bajísima formación catastral y, por ende, bajo nivel de actualización del mismo. 
Tabla 4. Desempeño del predial rural por cuartiles de área municipal, 1998-2010

\begin{tabular}{|c|c|c|c|}
\hline $\begin{array}{l}\text { Municipios por } \\
\text { cuartil de área }\end{array}$ & Medidas de desempeño del predial rural & Media & $\begin{array}{c}\text { Desviación } \\
\text { estándar }\end{array}$ \\
\hline \multirow{6}{*}{$\begin{array}{l}\text { Primer } \\
\text { cuartil }\end{array}$} & Tarifa efectiva predial rural \% & 4,30 & 5,34 \\
\hline & Tarifa nominal del predial rural \% & 6,08 & 1,99 \\
\hline & Recaudo predial per cápita (miles de pesos 2008) & 25,95 & 24,28 \\
\hline & Avalúo catastral rural per cápita (millones de pesos de 2008) & 7,10 & 9,65 \\
\hline & Número de actualizaciones catastrales (años) & 1,63 & 0,48 \\
\hline & Años desde la última actualización catastral & 6,53 & 3,50 \\
\hline \multirow{6}{*}{$\begin{array}{l}\text { Segundo } \\
\text { cuartil }\end{array}$} & Tarifa efectiva predial rural \% & 5,77 & 12,63 \\
\hline & Tarifa nominal del predial rural \% & 5,60 & 2,03 \\
\hline & Recaudo predial per cápita (miles de pesos 2008) & 24,46 & 33,95 \\
\hline & Avalúo catastral rural per cápita (Millones de pesos de 2008) & 5,37 & 5,48 \\
\hline & Número de actualizaciones catastrales (años) & 1,64 & 0,50 \\
\hline & Años desde la última actualización catastral & 6,68 & 3,58 \\
\hline \multirow{6}{*}{$\begin{array}{l}\text { Tercer } \\
\text { cuartil }\end{array}$} & Tarifa efectiva predial rural \% & 6,36 & 12,85 \\
\hline & Tarifa nominal del predial rural \% & 5,71 & 2,72 \\
\hline & Recaudo predial per cápita (miles de pesos 2008) & 20,82 & 20,75 \\
\hline & Avalúo catastral rural per cápita (Millones de pesos de 2008) & 4,81 & 5,37 \\
\hline & Número de actualizaciones catastrales (años) & 1,65 & 0,48 \\
\hline & Años desde la última actualización catastral & 7,77 & 6,11 \\
\hline \multirow{6}{*}{$\begin{array}{l}\text { Cuarto } \\
\text { cuartil }\end{array}$} & Tarifa efectiva predial rural \% & 8,51 & 14,84 \\
\hline & Tarifa nominal del predial rural \% & 5,74 & 2,67 \\
\hline & $\begin{array}{l}\text { Recaudo predial per cápita } \\
\text { (miles de pesos 2008) }\end{array}$ & 16,39 & 19,52 \\
\hline & $\begin{array}{l}\text { Avalúo catastral rural per cápita } \\
\text { (Millones de pesos de 2008) }\end{array}$ & 4,48 & 6,27 \\
\hline & $\begin{array}{l}\text { Número de actualizaciones catastrales } \\
\text { (años) }\end{array}$ & 1,58 & 0,50 \\
\hline & Años desde la última actualización catastral & 9,35 & 9,88 \\
\hline
\end{tabular}

Fuente: cálculos propios basado en datos del DNP para recaudo tributario municipal y datos de la Federación de Municipios para el área.

Respecto al nivel de ruralidad de los municipios, se observa en la tabla 5, que la tarifa efectiva es casi la mitad en los municipios más rurales que en los menos 
rurales, aunque la tarifa nominal es bastante homogénea entre los distintos cuartiles de ruralidad. Respecto al recaudo del predial, se observa un mayor recaudo del impuesto predial rural en los municipios de menor ruralidad. Por su parte, los avalúos catastrales rurales son menores a mayor ruralidad, lo cual puede estar asociado con la falta de actualización catastral en estos municipios que presentan un mayor número de años desde la última actualización con un rezago de casi 10 años. En términos del catastro, no se observa ningún patrón diferenciador entre los distintos niveles de ruralidad, con un promedio de 1.6 actualizaciones en el periodo. Esta información plantea interrogantes acerca de las razones por las cuales existe ese rezago catastral tan evidente en las zonas rurales. Autores como PNUD (2011), Kalmanovitz y López (2008), entre otros, sugieren que esto está asociado a la dificultad de realizar los catastros rurales; sin embargo, en un trabajo de Vargas y Villaveces (2016), se evidencia que los dueños de grandes extensiones de tierra tienen incentivos para frenar la actualización catastral a fin de mantener su activo a bajo costo y poder concentrar sin la presión a ser productivo.

Tabla 5. Desempeño del predial rural por cuartiles de ruralidad, 1998-2010

\begin{tabular}{|c|c|c|c|}
\hline $\begin{array}{l}\text { Municipios } \\
\text { por cuartil de } \\
\text { ruralidad }\end{array}$ & Medidas de desempeño del predial rural & Media & $\begin{array}{l}\text { Desviación } \\
\text { estándar }\end{array}$ \\
\hline \multirow{6}{*}{$\begin{array}{l}\text { Primer } \\
\text { cuartil }\end{array}$} & Tarifa efectiva predial rural \% & 11,15 & 21,81 \\
\hline & Tarifa nominal del predial rural \% & 5,55 & 2,01 \\
\hline & Recaudo predial per cápita (miles de pesos 2008) & 34,44 & 28,83 \\
\hline & Avalúo catastral rural per cápita (Millones de pesos de 2008) & 9,00 & 8,94 \\
\hline & Número de actualizaciones catastrales (años) & 1,76 & 0,42 \\
\hline & Años desde la última actualización catastral & 5,47 & 2,85 \\
\hline \multirow{6}{*}{$\begin{array}{l}\text { Segundo } \\
\text { cuartil }\end{array}$} & Tarifa efectiva predial rural \% & 3,91 & 4,85 \\
\hline & Tarifa nominal del predial rural \% & 5,25 & 1,76 \\
\hline & Recaudo predial per cápita (miles de pesos 2008) & 20,35 & 19.86 \\
\hline & Avalúo catastral rural per cápita (Millones de pesos de 2008) & 4,67 & 4,45 \\
\hline & Número de actualizaciones catastrales (años) & 1,61 & 0,49 \\
\hline & Años desde la última actualización catastral & 7,03 & 4,14 \\
\hline \multirow{3}{*}{$\begin{array}{l}\text { Tercer } \\
\text { cuartil }\end{array}$} & Tarifa efectiva predial rural \% & 4,18 & 3,38 \\
\hline & Tarifa nominal del predial rural \% & 6,05 & 3,65 \\
\hline & Recaudo predial per cápita (miles de pesos 2008) & 16,55 & 16,97 \\
\hline
\end{tabular}




\begin{tabular}{|l|l|c|c|}
\hline $\begin{array}{c}\text { Municipios } \\
\text { por cuartil de } \\
\text { ruralidad }\end{array}$ & \multicolumn{1}{|c|}{ Medidas de desempeño del predial rural } & Media & $\begin{array}{c}\text { Desviación } \\
\text { estándar }\end{array}$ \\
\hline \multirow{4}{*}{} & Avalúo catastral rural per cápita (Millones de pesos de 2008) & 3,89 & 4,81 \\
\cline { 2 - 4 } & Número de actualizaciones catastrales (años) & 1,61 & 0,52 \\
\cline { 2 - 4 } & Años desde la última actualización catastral & 7,70 & 5,91 \\
\hline \multirow{4}{*}{$\begin{array}{l}\text { Cuarto } \\
\text { cuartil }\end{array}$} & Tarifa efectiva predial rural \% & 5,66 & 5,81 \\
\cline { 2 - 4 } & Tarifa nominal del predial rural \% & 6,13 & 2,56 \\
\cline { 2 - 4 } & Recaudo predial per cápita (miles de pesos 2008) & 16,12 & 18,52 \\
\cline { 2 - 4 } & Avalúo catastral rural per cápita (Millones de pesos de 2008) & 4,05 & 4,97 \\
\cline { 2 - 4 } & Número de actualizaciones catastrales (años) & 1,54 & 0,49 \\
\cline { 2 - 4 } & Años desde la última actualización catastral & 9,82 & 8,94 \\
\hline
\end{tabular}

Fuente: cálculos propios basado en datos del DNP para recaudo tributario municipal y datos de ruralidad del DANE.

Como se observa en la tabla 6, frente a la concentración de la tierra, el comportamiento de las variables del predial rural no responde a lo esperado. La medida de concentración de la tierra es una proxy de la posición relativa de los grandes latifundistas y, por ende, de su potencial poder local. Según la revisión de literatura en Colombia, se espera que en los municipios con gran concentración de tierra haya un menor recaudo y mayores rezagos catastrales por cuenta de la influencia de los terratenientes sobre las decisiones del predial.

Sin embargo, tanto la tarifa efectiva como el recaudo del predial son más altos a mayor concentración, lo que indica que, al menos, hay un esfuerzo diferenciado según la concentración. Esto, como señalan Sánchez y España (2013) y Vargas y Villaveces (2016), puede explicarse por qué las grandes propiedades están formalizadas como mecanismo de jure para garantizar la propiedad y, por ende, las propiedades están incluidas en el catastro fiscal. Esta intuición se refuerza con los datos de avalúo catastral de los predios rurales, pues se observa que a mayor concentración, más altos los avalúos, lo que muestra que la tierra tiene un valor relativo superior en los predios más grandes. Respecto a las tarifas efectivas, estas tienden a ser más altas a mayor concentración de la tierra, lo cual complementa el dato del recaudo del predial y, también está asociado a la progresividad que rige este impuesto. No obstante, preocupa que las tarifas nominales sean casi invariables, lo cual indica que no se aplica la progresividad según el tamaño de la tierra. En términos del catastro, no hay diferencias importantes en el número de actualizaciones catastrales hechas y en el año de la última actualización catastral a partir de los cuartiles de distribución de 
la tierra. Esto llevaría a pensar que las razones del rezago catastral deben buscarse más allá de la estructura de la propiedad de la tierra.

Tabla 6. Desempeño del predial rural por cuartiles de Gini de la tierra, 2000-2010

\begin{tabular}{|c|c|c|c|}
\hline $\begin{array}{c}\text { Municipios por } \\
\text { cuartil Gini de la } \\
\text { tierra }\end{array}$ & Medidas de desempeño del predial rural & Media & $\begin{array}{c}\text { Desviación } \\
\text { estándar }\end{array}$ \\
\hline \multirow{6}{*}{$\begin{array}{l}\text { Primer } \\
\text { cuartil }\end{array}$} & Tarifa efectiva predial rural \% & 5,05 & 8,60 \\
\hline & Tarifa nominal del predial rural \% & 6,12 & 2,11 \\
\hline & Recaudo predial per cápita (miles de pesos 2008) & 15,77 & 18,74 \\
\hline & Avalúo catastral rural per cápita (millones de pesos de 2008) & 3,95 & 5,41 \\
\hline & Número de actualizaciones catastrales (años) & 1,63 & 0,491 \\
\hline & Años desde la última actualización catastral & 6,96 & 5,86 \\
\hline \multirow{6}{*}{$\begin{array}{c}\text { Segundo } \\
\text { cuartil }\end{array}$} & Tarifa efectiva predial rural \% & 4,79 & 9,23 \\
\hline & Tarifa nominal del predial rural \% & 5,69 & 2,68 \\
\hline & Recaudo predial per cápita (miles de pesos 2008) & 18,79 & 21,53 \\
\hline & Avalúo catastral rural per cápita (millones de pesos de 2008) & 4,60 & 6,19 \\
\hline & Número de actualizaciones catastrales (años) & 1,62 & 0,506 \\
\hline & Años desde la última actualización catastral & 6,70 & 5,31 \\
\hline \multirow{6}{*}{$\begin{array}{l}\text { Tercer } \\
\text { cuartil }\end{array}$} & Tarifa efectiva predial rural \% & 5,94 & 11,82 \\
\hline & Tarifa nominal del predial rural \% & 5,72 & 2,20 \\
\hline & Recaudo predial per cápita (miles de pesos 2008) & 24,32 & 25,98 \\
\hline & Avalúo catastral rural per cápita (millones de pesos de 2008) & 6,32 & 11,24 \\
\hline & Número de actualizaciones catastrales (años) & 1,66 & 0,48 \\
\hline & Años desde la última actualización catastral & 6,37 & 4,77 \\
\hline \multirow{6}{*}{$\begin{array}{l}\text { Cuarto } \\
\text { cuartil }\end{array}$} & Tarifa efectiva predial rural \% & 10,21 & 25,16 \\
\hline & Tarifa nominal del predial rural \% & 5,53 & 2,40 \\
\hline & Recaudo predial per cápita (miles de pesos 2008) & 31,70 & 39,79 \\
\hline & Avalúo catastral rural per cápita (Millones de pesos de 2008) & 7,01 & 9,79 \\
\hline & Número de actualizaciones catastrales (años) & 1,67 & 0,46 \\
\hline & Años desde la última actualización catastral & 6,72 & 5,25 \\
\hline
\end{tabular}

Fuente: cálculos propios basado en datos del DNP para recaudo tributario municipal y datos IGAC para distribución de la tierra. 
La medida de concentración política permite capturar la alta representación de un partido político y, asociado, un grupo de interés, en las elecciones locales, tanto para el concejo municipal como para la elección del alcalde. El caso de un concejo municipal con alta concentración política puede ser un indicador de una institución política poco representativa y con baja rendición de cuentas, situación que puede llevar a un bajo desempeño del predial rural, como sugieren Acemoglu, Ticchi y Vindigni (2006). Se observa en la tabla 7 que, en la medida en que existe mayor concentración política en los municipios, se presenta un menor recaudo del predial rural, que puede explicarse por la posibilidad de beneficiar intereses particulares representados en el concejo municipal en procura de menores impuestos sobre la tierra. Respecto al rezago en la actualización, se observa que a mayor concentración política, más alto el número de años desde la última actualización lo que sugiere que en ambientes de alta concentración política se posterga el compromiso de actualizar el catastro, resultado en línea con el menor recaudo.

Tabla 7. Desempeño del predial rural por cuartiles de concentración política, 1998-2010

\begin{tabular}{|c|c|c|c|}
\hline $\begin{array}{c}\text { Municipios por cuartil } \\
\text { de concentración } \\
\text { política en elecciones } \\
\text { municipales }\end{array}$ & Medidas de desempeño del predial rural & Media & $\begin{array}{l}\text { Desviación } \\
\text { estándar }\end{array}$ \\
\hline \multirow{6}{*}{ Primer cuartil } & Tarifa efectiva predial rural \% & 3,04 & 12,06 \\
\hline & Tarifa nominal del predial rural \% & 5,50 & 2,16 \\
\hline & Recaudo predial per cápita (miles de pesos 2008) & 17,34 & 0,09 \\
\hline & $\begin{array}{l}\text { Avalúo catastral rural per cápita (millones de pesos } \\
\text { de 2008) }\end{array}$ & 23,86 & 27,84 \\
\hline & Número de actualizaciones catastrales (años) & 1,53 & 7,61 \\
\hline & Años desde la última actualización catastral & 6,23 & 0,44 \\
\hline \multirow{6}{*}{ Segundo cuartil } & Tarifa efectiva predial rural \% & 3,76 & 9,21 \\
\hline & Tarifa nominal del predial rural \% & 5,37 & 8,19 \\
\hline & Recaudo predial per cápita (miles de pesos 2008) & 14,82 & 0,10 \\
\hline & $\begin{array}{l}\text { Avalúo catastral rural per cápita (Millones de pesos } \\
\text { de 2008) }\end{array}$ & 37,54 & 42,61 \\
\hline & Número de actualizaciones catastrales (años) & 1,39 & 6,44 \\
\hline & Años desde la última actualización catastral & 8,58 & 0,54 \\
\hline \multirow{2}{*}{ Tercer cuartil } & Tarifa efectiva predial rural \% & 4,14 & 7,79 \\
\hline & Tarifa nominal del predial rural \% & 6,14 & 10,84 \\
\hline
\end{tabular}


Marta Juanita Villaveces Niño

\begin{tabular}{|l|l|c|c|}
\hline $\begin{array}{c}\text { Municipios por cuartil } \\
\text { de concentración } \\
\text { política en elecciones } \\
\text { municipales }\end{array}$ & \multicolumn{1}{|c|}{ Medidas de desempeño del predial rural } & Media & $\begin{array}{c}\text { Desviación } \\
\text { estándar }\end{array}$ \\
\hline \multirow{5}{*}{ Tercer cuartil } & Recaudo predial per cápita (miles de pesos 2008) & 14,75 & 0,16 \\
\cline { 2 - 5 } & $\begin{array}{l}\text { Avalúo catastral rural per cápita (millones de pesos } \\
\text { de 2008) }\end{array}$ & 54,66 & 61,81 \\
\cline { 2 - 5 } & Número de actualizaciones catastrales (años) & 1,44 & 6,25 \\
\cline { 2 - 5 } & Años desde la última actualización catastral & 8,61 & 0,79 \\
\hline \multirow{5}{*}{ Cuarto cuartil } & Tarifa efectiva predial rural \% & 4,72 & 6,37 \\
\cline { 2 - 5 } & Tarifa nominal del predial rural \% & 6,74 & 13,19 \\
\cline { 2 - 5 } & Recaudo predial per cápita (miles de pesos 2008) & 14,74 & 0,09 \\
\cline { 2 - 5 } & $\begin{array}{l}\text { Avalúo catastral rural per cápita (millones de pesos } \\
\text { de 2008) }\end{array}$ & 68,20 & 87,56 \\
\cline { 2 - 5 } & Número de actualizaciones catastrales (años) & 1,69 & 5,08 \\
\cline { 2 - 5 } & Años desde la última actualización catastral & 8,85 & 0,59 \\
\hline
\end{tabular}

Fuente: Cálculos propios basado en datos del DNP para recaudo tributario municipal y datos de la Registraduría Nacional del Estado Civil para las elecciones locales.

En la tabla 8 se observa el comportamiento de las variables del predial respecto a la medida de eficiencia en la justicia. La medida de eficiencia en la justicia se toma como proxy de capacidad estatal. Se observa que en los municipios con una eficiencia en la justicia mayor, tanto la tarifa nominal como la tarifa efectiva del predial rural son mayores, en línea con la literatura que sugiere que la capacidad estatal incide de manera positiva en el recaudo y en el comportamiento de las tarifas. Sin embargo, no se observa una tendencia distinta en el número actualizaciones catastrales (alrededor de 6.8 años) y en los años desde la última actualización catastral.

Tabla 8. Desempeño del predial rural por cuartiles de eficiencia en la justicia, 2003-2009

\begin{tabular}{|c|l|c|c|}
\hline $\begin{array}{c}\text { Municipios } \\
\text { por cuartil de } \\
\text { eficiencia en la } \\
\text { justicia }\end{array}$ & \multicolumn{1}{|c|}{ Medidas de desempeño del predial rural } & Media & $\begin{array}{c}\text { Desviación } \\
\text { estándar }\end{array}$ \\
\hline \multirow{4}{*}{ Primer cuartil } & Tarifa efectiva predial rural \% & 6,18 & 13,72 \\
\cline { 2 - 4 } & Tarifa nominal del predial rural \% & 5,84 & 2,96 \\
\cline { 2 - 4 } & Recaudo predial per cápita (miles de pesos 2008) & 25,72 & 41,27 \\
\cline { 2 - 4 } & Avalúo catastral rural per cápita (millones de pesos de 2008) & 6,06 & 11,28 \\
\hline
\end{tabular}




\begin{tabular}{|c|c|c|c|}
\hline $\begin{array}{c}\text { Municipios } \\
\text { por cuartil de } \\
\text { eficiencia en la } \\
\text { justicia }\end{array}$ & Medidas de desempeño del predial rural & Media & $\begin{array}{l}\text { Desviación } \\
\text { estándar }\end{array}$ \\
\hline & Número de actualizaciones catastrales (años) & 1,65 & 0,514 \\
\hline & Años desde la última actualización catastral & 6,83 & 6,64 \\
\hline \multirow{6}{*}{ Segundo cuartil } & Tarifa efectiva predial rural \% & 6,68 & 11,91 \\
\hline & Tarifa nominal del predial rural \% & 5,88 & 2,08 \\
\hline & Recaudo predial per cápita (miles de pesos 2008) & 21,01 & 22,29 \\
\hline & Avalúo catastral rural per cápita (millones de pesos de 2008) & 5,84 & 9,79 \\
\hline & Número de actualizaciones catastrales (años) & 1,66 & 0,47 \\
\hline & Años desde la última actualización catastral & 6,73 & 5,00 \\
\hline \multirow{6}{*}{ Tercer cuartil } & Tarifa efectiva predial rural \% & 8,04 & 23,94 \\
\hline & Tarifa nominal del predial rural \% & 5,12 & 1,85 \\
\hline & Recaudo predial per cápita (miles de pesos 2008) & 23,10 & 21,64 \\
\hline & Avalúo catastral rural per cápita (millones de pesos de 2008) & 5,26 & 6,21 \\
\hline & Número de actualizaciones catastrales (años) & 1,68 & 0,46 \\
\hline & Años desde la última actualización catastral & 6,26 & 4,21 \\
\hline \multirow{6}{*}{ Cuarto cuartil } & Tarifa efectiva predial rural \% & 5,04 & 6,14 \\
\hline & Tarifa nominal del predial rural \% & 5,94 & 2,08 \\
\hline & Recaudo predial per cápita (miles de pesos 2008) & 20,73 & 23,06 \\
\hline & Avalúo catastral rural per cápita (Millones de pesos de 2008) & 4,71 & 5,71 \\
\hline & Número de actualizaciones catastrales (años) & 1,60 & 0,50 \\
\hline & Años desde la última actualización catastral & 6,93 & 5,12 \\
\hline
\end{tabular}

Fuente: cálculos propios basado en datos del Departamento Nacional de Planeación para recaudo tributario municipal y datos de Consejo Superior de la Judicatura para calcular eficiencia en la justicia.

Por último, la presencia de actores ilegales (paramilitares y guerrilla) y la evidencia de algún tipo de captura de estos actores deterioran el impuesto predial rural en términos de la tarifa efectiva del predial rural y un nivel de recaudo algo inferior al de los municipios sin captura de actores ilegales. Por su parte, se observa que en municipios con algún tipo de captura de la política por parte de la guerrilla, el recaudo del predial rural es menor que el de los municipios sin captura (ver tabla 9). 
Tabla 9. Desempeño del predial rural en municipios con algún tipo de captura ilegal, 2000-2008

\begin{tabular}{|l|l|c|}
\hline \multicolumn{1}{|c}{ Tipo de captura } & \multicolumn{1}{|c|}{ Medidas de desempeño del predial rural } & Media \\
\hline \multirow{4}{*}{ Paramilitares } & Tarifa efectiva predial rural \%o & 2,43 \\
\cline { 2 - 3 } & Tarifa nominal del predial rural \%o & 5,33 \\
\cline { 2 - 3 } & Recaudo predial per cápita (miles de pesos 2008) & 13,73 \\
\hline \multirow{5}{*}{ Guerrilla } & Tarifa efectiva predial rural \%o & 2,75 \\
\cline { 2 - 3 } & Tarifa nominal del predial rural \%o & 5,52 \\
\cline { 2 - 3 } & Recaudo predial per cápita (miles de pesos 2008) & 10,26 \\
\hline \multirow{5}{*}{ Son algún tipo de captura captura } & Tarifa efectiva predial rural \%o & 2,84 \\
\cline { 2 - 3 } & Tarifa nominal del predial rural \%o & 5,34 \\
\cline { 2 - 3 } & Recaudo predial per cápita (miles de pesos 2008) & 14,20 \\
\hline & Tarifa efectiva predial rural \%o & 4,02 \\
\cline { 2 - 3 } & Tarifa nominal del Predial rural \%o & 5,76 \\
\cline { 2 - 3 } & Recaudo Predial per cápita (miles de pesos 2008) & 14,27 \\
\hline
\end{tabular}

Fuente: cálculos propios basado en datos del DNP para recaudo tributario municipal y datos de captura de López (2010).

Por otra parte, según la literatura consultada, cuando las élites locales utilizan la coerción y los mecanismos de hecho para salvaguardar su fuente de poder económico y político, los resultados son negativos para el desempeño económico -tributación-, en especial en términos del recaudo del predial. Sin embargo, al parecer, no existe un hecho estilizado entre la captura del poder local y las tasas efectivas del predial rural, el avaluó catastral y el rezago en la actualización catastral. Este resultado va en línea con la idea de que en un país con una larga historia con el poder coercitivo, no debería haber efectos en la recaudación de ingresos. Además, el canal de la asociación no es la violencia en sí misma, son los vínculos entre los gobernantes y los actores armados ilegales. En otras palabras, no es la violencia en sí la que afecta la tributación sino los vínculos entre autoridades locales con grupos al margen de la ley.

\section{CONCLUSIONES}

El análisis aquí presentado permite ver que hay un comportamiento diferenciado del predial rural según las instituciones políticas locales. Es decir, la manera en que se implementa este impuesto varía según la calidad institucional local, además de la estructura de la propiedad. Esta evidencia va en línea con la literatura institucional y los análisis sobre la tierra en Colombia. 
Se observa que el recaudo del predial es mayor en entornos de concentración económica y menor con concentración política, aunque no se observan cambios en el rezago catastral según cuartiles de concentración de la tierra, pero sí a medida que aumenta la concentración política. Respecto a la tarifa nominal, no se observan cambios según entornos institucionales, lo que sugiere la no discriminación de la tarifa, al menos, según niveles de concentración de la tierra. Adicional, frente a la captura del poder local por actores ilegales, el cambio más evidente es un menor recaudo en entornos de captura por guerrilleros. Estos hechos estilizados invitan a seguir pensando en el alcance del entorno institucional en el desempeño tributario, especialmente el predial rural. Se sugiere que la concentración política puede jugar en contra de un mayor recaudo al igual que la presencia de grupos al margen de la ley, temas que deben considerarse a la hora de pensar en fortalecer la capacidad estatal local. A su vez, el rezago catastral parece explicar buena parte del desempeño diferenciado del predial rural, situación que en parte se relaciona con entornos de alta concentración política, sugiriendo que la decisión de actualizar puede estar afectada por intereses privados de los dueños de la tierra. Por último, la casi homogénea tarifa nominal sugiere que no se implementa la lógica de la progresividad en la tarifa, propia de la naturaleza del impuesto predial en Colombia.

\section{BIBLIOGRAFÍA}

Acemoglu, Daron; Johnson, Simon y Robinson, James (2005). Institutions as Fundamental Determinants of Long-Run Growth, p. 385-472. En: Handbook of Economic Growth, Philippe Aghion and Steven Durlauf (Eds), Volume 1A, Amsterdam; North-Holland, 1138p.

Acemoglu, Daron y Robinson, James (2008). Persistence of Power, Elites and Institutions. En: American Economic Review, Vol. 98, No. 1, p. 267-293.

Acemoglu, Daron; Ticchi, Davide y Vindigini, Andrea (2006). Emergence and Persistence of Inefficient States. Massachusetts Institute of Technology. Department of Economics. En: Working Paper Series No. 06-32, 70p.

Aidt, Toke (2003). The Economic Analysis of Corruption: A Survey. En: The Economic Journal, Vol. 113, No. 491, p. 632-652.

Besley, T, Persson, Ty Sturm, D (2005). Political Competition and Economic Performance: Theory and Evidence from the United States. En: NBER Working Paper, No. 11484 Issued in July 2005, 53p.

Besley, T y Preston, I (2002). Accountability and Political Competition: Theory and Evidence. Weather Center for International Affairs, Harvard University, 30p.

Bird, Richard (2008). Tax Challenges Facing Developing Countries, Inaugural Lecture of the Annual Public Lecture Series of the National Institute of Public Finance and Policy, New Delhi, India, March 12, 31p. 
Bird, Richard y Enid Slack (2007). Taxing Land and Property in Emerging Economies: Raising Revenue... and More? p. 204-248. En: G.K. Ingram and Y-H. Hong, (eds.), Land Policies and Their Outcomes (Cambridge, MA: Lincoln Institute of Land Policy), 464p.

Bird, R. y Slack, E. (2004). International Handbook of Land Property Taxation. Cheltenham, UK: Edward Elger, $311 \mathrm{p}$.

Bird, Richard y Zolt, Eric (2003). Introduction to Tax Policy Design and Development. Draft prepared for a course on Practical Issues of Tax Policy in Developing Countries, World Bank, April 28-May 1, 39p.

Bordignon, Massimo; Cerniglia, Floriana y Revelli, Federico (2002). In Search for Yardstick Competition: Property Rates and Electoral Behavior in Italian Cities, CESifo Working Paper No. 644, Center for Economic Studies and Institute for Economic Research, Munich, 28 p.

Brennan, Geoffrey y Buchanan, James (2006). The Power to Tax. Analytical Foundation of a Fiscal Constitution. Cambridge: Cambridge University Press, 248p.

Chemonics International Inc (2004). Colombia: la perspectiva del impuesto predial en áreas rurales. Washington: LAC Bureau Poverty Reduction, USAID.

Currie, L (1952). The Basis of a Development Program for Colombia: Report of a Mission. Washington: International Bank for Reconstruction and Development, 642p.

De Cesare, C. (2010). Panorama del Impuesto Predial en América Latina. Lincoln Institute of Land Policy, Working Paper, No. WP10CC1SP.

Della Porta, D y Vanucci, A. (2005). The Governance Mechanisms of Corrupt Transactions, p. 152-180. En: Lambsdorff J. G., Taube M., Schramm, M. (eds.). The New Institutional Economics of Corruption, London, Routledge, 272p.

DNP- Departamento Nacional de Planeación - (2015). Documento Conpes 3852 de 2015, 21p.

Di John, Jonathan (2006). The Political Economy of Taxation and Tax Reform in Developing Countries, Research Paper UNU-WIDER, No. 76.

Duff, David (2003). Benefit Tax and User Fees in Theory and Practice. Research Paper Submitted to Ontario role of Government Panel, 81p.

Echavarría, Hernán (1987). Tenencia de la tierra y desarrollo económico y social. Disertación para ingresar como miembro de número a la Académica Colombiana de Ciencias Económicas, $28 \mathrm{p}$.

Echavarría, Hernán (2002). En qué momento se atascó Colombia. Bogotá: Instituto para la Cultura Económica, 27p.

Feld, L. y G. Kirchgässner (2001). The Political Economy of Direct Legislation: Direct Democracy and Local Decision-Making, Economic Policy, Vol. 16, No. 33, octubre, p. 329-367.

Fjeldstad, Odd-Heldge (2004). To Pay or not to Pay. Citizens view on taxation in local authorities in Tanzania. Chr Michelsen Institute WP, 25p.

Hofstetter, Mark (1997). La tierra, los impuestos y la economía política. En: Desarrollo y Sociedad, No. 40, p 217-271. 
Iregui, Ana María; Melo, Ligia y Ramos, Jorge (2005). El impuesto predial en Colombia: factores explicativos del recaudo. En: Revista de Economía del Rosario, Vol. 8, No. 1, p 25-56.

Iregui, Ana María; Melo, Ligia y Ramos, Jorge (2003). El impuesto predial en Colombia: factores explicativos del recaudo. En: Revista de Economía del Rosario, No. 8, p, 25-58.

Iregui, Ana María; Ramos, Jorge y Saavedra, Luz Amparo (2001). Análisis de la Descentralización fiscal en Colombia. En: Borradores de Economía, No 175. Banco de la República, 35 p.

Kalmanovitz, Salomón (2010). Nueva Historia Económica de Colombia. Bogotá: Taurus, Universidad Jorge Tadeo Lozano, 360 p.

Kalmanovitz, Salomón y López, Enrique (2008). Distribución, Narcotráfico y Conflicto. Mimeo.

Kalmanovitz, Salomón y López, Enrique (2007). Aspectos de la agricultura colombiana en el siglo XX. En: Robinson, J and Urrutia, M. Economía Colombiana del Siglo XX. Un análisis cuantitativo. Bogotá: Fondo de Cultura Económica y Banco de la República, 704p.

Kitchen, Harry (2003). Property Taxation: Issues in Implementation. Prepared for CEPRA II Project, AUCC, 20p.

Leibovich, José (2005). El impuesto predial. En: Núñez, J. (Eds). Diagnóstico Básico de la situación de los ingresos por impuestos del orden municipal en Colombia. Documento Cede 2005044, $137 \mathrm{p}$.

López, Claudia (2010). Y refundaron la patria... De cómo mafiosos y políticos reconfiguraron el Estado colombiano. Bogotá: Debate, 524 p.

Machado, Absalón (1990). La institucionalidad en el sector agropecuario. En: Hernández, A.; Machado, A. y Montenegro (Eds). La organización institucional del sector agropecuario. Bogotá: Comisión Presidencia para la Reforma de la Administración Pública el Estado Colombiano.

Machado, Absalón (1998). Reforma Agraria. Una ilusión que terminó en fracaso. En: Revista Credencial Historia, No. 119.

Müller, S y Zouridis, S (2012). Law and Justice: A Strategy Perspective. The Hague: Torkel Opsahl Academic EPublisher, 397 p.

North, Douglass (1990). Institution, Institutional Change and Economic Performance. Cambridge: Cambridge University Press, 159 p.

Oates, Wallace y Schwab, Robert (1997). The Impact of Urban Land Taxation: The Pittsburg Experience. En: National Tax Journal, Vol. 50. No. 1, p. 1-21.

Offstein, Norman (2005). National, Departmental and Municipal Rural Agricultural Land Distribution in Colombia: Analyzing the Web of Inequality, Poverty and Violence. Documento Cede 2005-37, Universidad de los Andes, 41 p.

Palacios, Marco (2002). País de ciudades, p. 549-582. En: Safford y Palacios (Eds). Colombia: País Fragmentado, Sociedad Dividida. Su Historia. Bogotá: Grupo Editorial Norma, 742p.

Penning, Jean Philippe (2003). Evaluación del proceso de descentralización en Colombia. En: Economía y Desarrollo, Vol. 2, No. 1, p 123-149. 
Perez, Manuel Enrique (2004). La conformación territorial en Colombia: entre el conflicto, el desarrollo y el destierro. En: Cuadernos de Desarrollo Rural, Universidad Javeriana, No. 051, p 61-90.

PNUD (2011). Colombia Rural. Razones para la Esperanza. Informe Nacional de Desarrollo Humano, 2011. Bogotá: Programa de las Naciones Unidas para el Desarrollo, 120 p.

Profeta, Paola y Scabrosetti, Simona (2007). Political Economy Issues of Taxation in Latin America, Department of Publics and Environmental Economics, University of Pavia, 23 p.

Reyes, Álvaro (2009). Guerreros y campesinos. El despojo de la tierra en Colombia. Bogotá: FESCOL, Grupo Editorial Norma, 378 p.

Reyes, Álvaro (2008) Los dilemas de la tierra. El Espectador, 22 feb. 2008.

Sánchez, Fabio y España, Irina (2013). Estructura, Potencial y Desafíos del Impuesto Predial en Colombia. Documentos CEDE Centro de Estudios sobre Desarrollo Económico, No 48, 34 p.

Scholz, John (1998). Trust, Taxes and Compliance, p. 135-166. En: Braithwaite and Levi (Eds), Trust and Governance. New York: Russell Sage Foundation, 400 p.

Sokoloff, Kenneth y Zolt, Eric (2007). Inequality and the Evolution of Institutions of Taxation: Evidence from the Economic History of the Americas, mimeo, University of Chicago Press, $57 \mathrm{p}$.

Slack, Enid (2010). The Property Tax ... in Theory and Practice. IMFG Working Paper No. 02, University of Toronto, Institute on Municipal Finance and Government and Munk School of Global Affairs, 17p.

Tanzi, Vito (1995). Fiscal Federalism and Decentralization. A review of some efficiency and macroeconomic aspects Annual World Bank Conference on Development Economics, p. 295-316.

Taylor, M y Richman, R. (1965). Fiscal Survey of Colombia. Joint Tax Program of the Organization of American States and the Inter-American Development Bank. Baltirmore: Johns Hopkings Press, 276p.

Thoumi, Francisco (1999). La relación entre corrupción y narcotráfico: un análisis general y algunas referencias a Colombia. En: Revista de Economía de la Universidad del Rosario, Vol. 2. No 1, p. 11-33.

Uslaner, Eric (2003). Tax Evasion, Trust and the Strong Arm of the Law, Prepared for the Conference Tax Evasion, Trust and State Capacity, Switzerland, p. 17-19.

Vásquez, J.G (2011). El ruido de las cosas al caer. Bogotá: Alfaguara, 265p.

Vargas, J. F. y Villaveces, M.J. (2016). Rural Property Tax Revenue in the Face of Economic Concentration and Political Competition: Evidence from Colombia. CAF-Working paper; No. 2016/05, Caracas: CAF, 29p.

World Bank (2008). The Political Economy of Taxation in Developing Countries. Challenges to Practitioners. Washington D.C: International Finance Corporation

Zapata, Juan Gonzalo (1991). Evaluación de las principales leyes de descentralización económica en la década de los 80. En: Gaitán, Pilar, López, Andrés; Pulido, Luz Margoth, Zapata, Juan Gonzalo y Knool, Joachi (Eds), Comunidad, Alcaldes y Recursos Fiscales. Bogotá: Fescol, 222p. 